\title{
Behavioral Economics Interventions in Clinical Decision Support Systems
}

\author{
Insook Cho ${ }^{1,2}$, David W. Bates ${ }^{2,3,4}$ \\ 1 Nursing Department, Inha University, Incheon, South Korea \\ 2 The Center for Patient Safety Research and Practice, Division of General Internal Medicine and \\ Primary Care, Brigham and Women's Hospital, Boston, MA, USA \\ 3 Harvard Medical School, Boston, MA, USA \\ ${ }_{4}$ Partners Healthcare Systems, Inc., Wellesley, MA, USA
}

\begin{abstract}
Summary
Background: Clinical decision support (CDS) systems can improve safety and facilitate evidence-based practice. However, clinical decisions are often affected by the cognitive biases and heuristics of clinicians, which is increasing the interest in behavioral and cognitive science approaches in the medical field. Objectives: This review aimed to identify decision biases that lead clinicians to exhibit irrational behaviors or responses, and to show how behavioral economics can be applied to interventions in order to promote and reveal the contributions of CDS to improving health care quality.

Methods: We performed a systematic review of studies published in 2016 and 2017 and applied a snowball citationsearch method to identify topical publications related to studies forming part of the BEARI (Application of Behavioral Economics to Improve the Treatment of Acute Respiratory Infections) multisite, cluster-randomized controlled trial performed in the United States.

Results: We found that 10 behavioral economics concepts with nine cognitive biases were addressed and investigated for clinician decision-making, and that the following five concepts, which were actively explored, had an impact in CDS applications: social norms, framing effect, status-quo bias, heuristics, and overconfidence bias.

Conclusions: Our review revealed that the use of behavioral economics techniques is increasing in areas such as antibiotics prescribing and preventive care, and that additional tests of the concepts and heuristics described would be useful in other areas of CDS. An improved understanding of the benefits and limitations of behavioral economics techniques is also still needed. Future studies should focus on successful design strategies and how to combine them with CDS functions for motivating clinicians.
\end{abstract}

\section{Keywords}

Clinical decision support systems; behavioral economics; cognitive science; decision bias

Yearb Med Inform 2018:114-21

http://dx.doi.org/10.1055/s-0038-1641221

\section{Introduction}

One of the most important developments in clinical decision support (CDS) over the past 2-3 years has been the utilization of behavioral theories and techniques from behavioral economics and other domains such as social psychology for improving the likelihood of success. The field of behavioral economics has designed and tested interventions (often called "nudges") that utilize non-rational, non-conscious features of human thought to improve decisions [1, 2]. For example, people are less likely to litter or cheat on their taxes, if they believe that relatively few people do this [3-5]. Some authors have suggested that nudges could be used more frequently in health care [1,6-8], for example for discouraging undesirable ordering behaviors of physicians or designing decision aids for patients.

Clinical decision-making is defined as the process of examining and comparing the possibilities, risks, uncertainties, and options for choosing a course of action $[9,10]$. The application of CDS has produced benefits in many areas, including medication safety, diagnostic test ordering, and reducing care costs. However, the impacts on practice have often been small, with any impact on clinical outcomes being unclear in most areas [11-14]. It is likely that CDS will become more complex, especially by leveraging new approaches such as big-data techniques and machine learning. However, any clinical benefit will be substantially affected by whether clinicians will choose to implement the suggested approaches. Most CDS approaches historically have assumed that clinicians are rational, deliberate, and will respond positively to evidence-based suggestions [9, 10]. In contrast, behavioral models suggest that clinicians tend to make decisions rapidly and often engage in automatic behaviors, and so their decision-making may be best influenced by emotional and social factors using techniques such as nudges and other forms of social motivation [15-18].

Traditional economics theory suggests that humans behave as fully informed and rational actors. In contrast, behavioral economics combines the fundamental aspects of economics theory with insights from psychology about the common biases that influence decision-making [19, 20]. Behavioral economics suggests that decision-making involves predictable biases [1], which allows constructed interventions to anticipate and counteract biases to produce socially desirable outcomes, and even small changes to significantly affect the decision-making environment. For example, the use of appropriate default settings can have a major impact and foster beneficial outcomes [1, 15, 21]. Many studies have focused on improving financial behaviors, such as automatically including employees in voluntary retirement savings programs but also allowing them to opt out [1]. The influence of behavioral economics on behavior in many domains has increased the focus on its use in health care [22-24].

Insights from behavioral economics can be used to improve the likelihood of successful CDS. In this paper we identify some key decision biases that ordinarily lead to irrational behaviors or responses of clinicians and show how interventions based on behavioral economics can promote and reveal the contributions of CDS to the quality 
of care. We also introduce and highlight current successful examples of behavioral economics applications in CDS studies. These cases will provide a better understanding of the role of decision biases and heuristics, and how to use them to intervene and improve the motivation and behavior of clinicians.

\section{Background}

Behavioral economics emerged against the backdrop of the traditional economics approach known as the rational-choice model. Traditional economics theory states that people tend to "make good choices in contexts in which they have experience, good information, and prompt feedback," [1] such as choosing among ice cream flavors, while they often make poor choices in contexts in which "they are inexperienced and poorly informed and in which feedback is slow or infrequent," [1] such as choosing an investment portfolio or a drug plan.

Studies on behavioral economics and psychology have documented and explained many of the habits, biases, and tendencies that underlie decision-making, particularly the ways in which it deviates from that predicted by economics theory. These deviations are neither random nor trivial, instead they represent systematic patterns of cognitive biases with enormous implications for health care [25].

Behavioral economics has been applied to health care in recent years. A systematic literature review [16] of cognitive biases and heuristics in medical decision-making found 19 types of cognitive biases and heuristics, with loss/gain framing bias, relative-risk bias, availability bias, and omission bias being studied the most. Sixty-eight percent of the studies found a bias or heuristics, and $34 \%$ assessed clinicians [16]. Behavioral economics techniques have recently been applied to improving the quality of clinical care, including CDS. For example, it was found that sending a letter to the top $20 \%$ of antibiotics prescribers in England stating that their practice was prescribing antibiotics at a higher rate than $80 \%$ of practices in the NHS Local Area Team resulted in significantly fewer antibiotics being dispensed [17].
Behavioral economics is also closely related to interventions for improving the quality of clinical care that frequently rely upon changing the practice of clinicians' behaviors, such as reducing inappropriate treatments or diagnostic tests. Several trials have investigated consensus-recommended best practices in designing and implementing quality-improvement interventions that include provider education, audits and feedback, checklists, frontline staff or target populations, or providing direct financial incentives [18]. However, it is unclear if these practices influence the behavior of clinicians. Another approach is applying concepts from the behavioral sciences to changing behavior, such as using social cues and subtle changes in the clinical environment. Related investigations have applied behavioral science models to identify new social and cognitive devices for gently nudging the decision-making of clinicians while preserving their freedom of choice [26]. Such approaches support the goal of effective, evidence-based treatment in health care with appropriate adoption and responses to CDS.

\section{Methods}

We searched for relevant publications using two methods: a systematic review and snowball citation searching.

\subsection{Systematic Review}

\section{Search Strategy}

Three databases [PubMed, Web of Science, and CINAHL (EBSCO)] were searched for all relevant studies published during 2016 and 2017. The three main concepts of clinical decision-making, CDS, and behavior were mapped to the most-relevant controlled vocabulary using MeSH (Medical Subject Headings) terms, and free-text terms related to behavior change, behavioral approach, or behavioral economics were added where necessary.

\section{Study Selection}

This review identified studies involving behavioral economics concepts or heuristics as an intervention feature in a CDS system or in the health-care context. We excluded articles that only reported a CDS system development process, cognitive-behavior therapy as treatment, including animal behavior, evaluating non-behavior economics interventions, or technical reports on electronic health records (EHRs), mobile applications or platforms, as well as systematic reviews of all types of CDS systems.

\section{Screening and Study Grouping}

We classified the behavioral economics concepts or psychology principles used in studies related to clinical decision-making by providers or patients. Articles were first screened for relevance based on their titles and abstracts, followed by an evaluation of the full texts. Two reviewers independently screened articles at each stage (IC and the research assistant of a $\mathrm{PhD}$ student). Disagreements were resolved by discussions between the two reviewers. The overall Kappa value was calculated to assess inter-rater reliability [27].

One reviewer (IC) performed data abstraction focusing on concepts of behavioral economics or psychology principles addressed, citation information, study design, decision context, main intervention concepts, controls (if applicable), and decision-making outcomes. If an article included in the review cited a CDS system, then information from these sources was used to supplement the data obtained from the article.

Thematic grouping was applied to all studies identified in the systematic review. Data obtained from the articles were used to classify behavioral economics concepts or psychology principles related to clinical decision-making that were employed in the studies.

\subsection{Snowball Citation Searching}

We selected three recent reports on the meaningful application of CDS for behavior interventions aimed at improving the prescribing decisions made by physicians [28-30]. The studies formed part of the Application of Behavioral Economics to Improve the Treatment of Acute Respiratory Infections (BEARI) study, a multisite, clus- 
ter-randomized controlled trial performed at various practices in Illinois, Massachusetts, and southern California. We investigated the references in the three publications to find other sources related to the application of behavioral economics to CDS. Authors, titles, abstracts, and captions along with descriptors and other metadata were also examined, and these terms were used to reformulate the search terms applied in subsequent searches. We further used a snowball citation-search method to find key papers on studies in the PubMed database that refer to these papers. We identified topical studies and the sources that the authors used, the frequency of citations, and which authors were cited. This strategy identified authors who had referenced specific publications.

\section{Results}

The literature search found a total of 816 articles among which 462 were eligible for screening after duplicate removal. Title and abstract screening resulted in the retention of 32 articles, then full-text screening identified 12 articles that met the target criteria and so were included in our classification. The overall Kappa value for the screening process was 0.70 , reflecting substantial agreement [31]. The 12 selected articles reported on 10 distinct studies. Among these studies, three addressed monitoring and individual feedback [32-34], two compared framed presentations [35, 36], two addressed heuristics [37, 38] and [39], one was about social norms [40], one addressed the ordering effect [41], and one used a combination of overconfidence, risk aversion, and herding $[42,43]$. Figure 1 presents the flowchart of this systematic review.

Table 1 summarizes the behavioral economics concepts and psychology principles used in EHR-based CDS systems and to aid decisions made by patients. EHR-based CDS systems were used to choose treatment options such as medication prescriptions, preventive care, and chronic disease management, rather than for diagnoses.

The following five behavioral economics concepts have frequently been considered in CDS studies: social norms, framing effect,

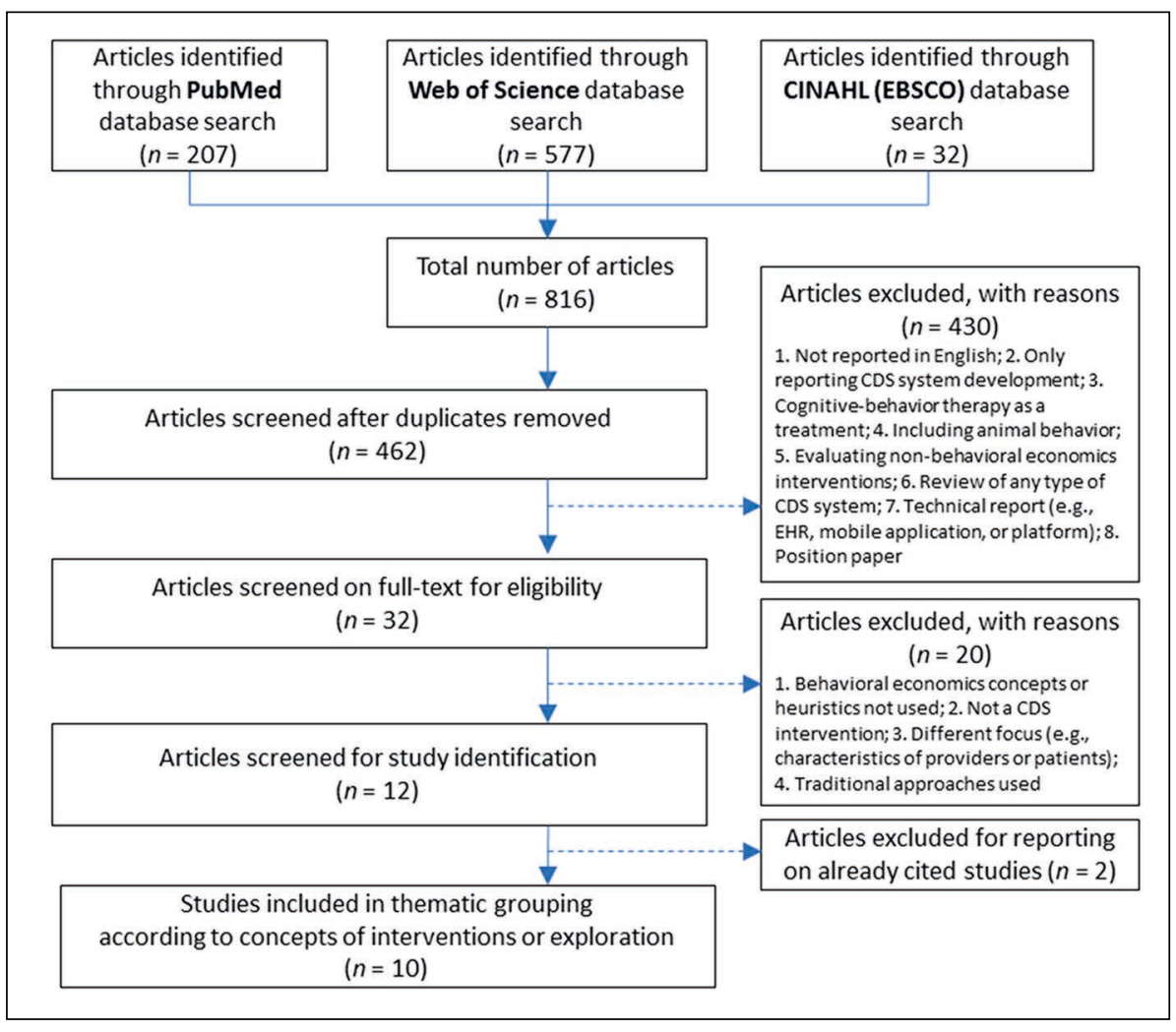

Fig. 1 Flowchart of study inclusion

status-quo bias, heuristics, and overconfidence bias. Below we introduce applications and example studies related to each approach in the field of behavioral economics.

\subsection{Social Norms}

Social norms are informal understandings that govern the behavior of the members of a society. Norms that conflict with the behaviors of the dominant society or culture may still be transmitted and maintained within small subgroups of the society. The concepts closely related to social norms are peer comparison and accountable justification. The social psychology literature indicates that feedback from clinicians to a health-care provider on his or her recent performance will have a greater impact when the characteristics of these clinicians are more similar to those of the provider. This may be due to greater similarity between the peer group and the target individual increasing the difficulty of disregarding such comparison data. In addition, the use of local or provincial norms may indicate greater changes compared to using global norms.

Accountability also refers to social pressures to justify one's views or decisions to others. Expectations of accountability are an implicit or explicit constraint on virtually everything people do ("If I do this, how will others react?") [45]. Accountability serves to enforce vital societal norms and bridges between the individual and the institutional or social structure to influence individual behavior via social pressures. However, accountability might not affect the direction of judgment, or it might increase or decrease judgmental bias [45]. Psychology studies [46] have found that descriptive norms influence individuals more when the setting in which those norms are formed is comparable to the present setting. Therefore, the motivational power of normative appeals could be greater when describing group behavior that occurred in the setting that most closely matched the immediate situational circumstances of the individual. This is similar to 
Table 1 Behavioral economics concepts and psychology principles relevant to clinical decision support for clinicians and patients

\begin{tabular}{|c|c|}
\hline Concept & Definition \\
\hline Social norms $[3,4,44,45]$ & Tendency to uphold one's social reputation based on descriptive or local norms. \\
\hline Framing effect $[46,47]$ & $\begin{array}{l}\text { Expression of logically equivalent information in different ways, to maximize the } \\
\text { receptivity of clinicians. }\end{array}$ \\
\hline Status-quo bias $[1,48]$ & $\begin{array}{l}\text { A preference for familiarity. People tend to resist change and prefer the current } \\
\text { state of affairs. }\end{array}$ \\
\hline Loss aversion/risk aversion [49-51] & $\begin{array}{l}\text { A heightened tendency to focus on avoiding losses, even if this means engaging in } \\
\text { risky behavior. }\end{array}$ \\
\hline Decision fatigue $[52,53]$ & $\begin{array}{l}\text { Being presented with the same circumstances repeatedly will tend to make people } \\
\text { lazy and perform worse, making bad decisions more likely. }\end{array}$ \\
\hline $\begin{array}{l}\text { Order effects: primacy and recency } \\
{[54,55]}\end{array}$ & $\begin{array}{l}\text { The effect ordering has on the relative utility weights associated with the attributes. } \\
\text { Ordering effects may be observed as a consequence of the order in which choice } \\
\text { sets, scenarios, or attributes appear in a questionnaire. }\end{array}$ \\
\hline Salience effect [56-59] & Increasing the distinctness of important material so that it will be noticed. \\
\hline IKEA effect [60] & Overvaluing a product to which one has contributed time and effort. \\
\hline Herding [61] & Decisions influenced by other colleagues. \\
\hline Heuristics $[1,16,62]$ & $\begin{array}{l}\text { Mental shortcuts based on pattern recognition that drive most decision-making } \\
\text { take precedence over rule-based decisions (analytic cognitive process), by springing } \\
\text { to mind spontaneously and effortlessly. }\end{array}$ \\
\hline Cognitive bias: overconfidence $[9,63]$ & $\begin{array}{l}\text { Errors in probability judgments due to overestimating past appropriate behaviors } \\
\text { and future successes. }\end{array}$ \\
\hline Cognitive bias: anchoring $[9,64]$ & $\begin{array}{l}\text { The tendency to perceptually lock onto features of the patient's initial presentation } \\
\text { too early during the diagnosis, and failing to adjust this initial impression in the } \\
\text { light of subsequent information. }\end{array}$ \\
\hline Cognitive bias: availability $[9,62]$ & $\begin{array}{l}\text { The disposition to judge things as being more likely (or occurring frequently) if they } \\
\text { readily come to mind. For example, recent experience of a disease may increase the } \\
\text { likelihood of it being diagnosed. }\end{array}$ \\
\hline Cognitive bias: hindsight $[9,62]$ & $\begin{array}{l}\text { Knowing the outcome may profoundly influence the perception of past events and } \\
\text { prevent an accurate appraisal of what actually occurred. }\end{array}$ \\
\hline Cognitive bias: commission $[9,65]$ & Tendency toward action rather than inaction. \\
\hline Cognitive bias: omission $[9,65]$ & Judging harmful commissions as worse than the corresponding omissions. \\
\hline Cognitive bias: representativeness $[9,62]$ & Overemphasizing evidence that strongly resembles a class of events. \\
\hline Cognitive bias: relative risk [62] & $\begin{array}{l}\text { Being more likely to choose an option when presented with the relative risk than } \\
\text { the absolute risk. }\end{array}$ \\
\hline Too much choice (alternatives) $[9,62]$ & Choosing a given option more often when there are more alternatives. \\
\hline
\end{tabular}

the so-called collective conservatism phenomenon, which is the tendency for people to conform to group norms. This principle can be utilized when attempting to change behavior [1].

The BEARI study compared the effect of peer comparison with two other types of intervention [29]. The investigators sent feedback on the performance rate to each provider via email messages that contained either "You are a top performer" or "You are not a top performer" on the subject line, based on a performance-rate cutoff of the best $10 \%$ providers. This intervention resulted in a significant decrease in the mean antibiotics prescribing rates [66]. The use of achievable benchmarks was found to significantly enhance the effectiveness of physician performance feedback compared to this being based on their own performance relative to the mean performance.

The accountable justification prompted clinicians to enter a free-text justification for prescribing antibiotics on the EHRs that other providers could see, with the statement "No justification for prescribing antibiotics was given" being entered if the clinician did not enter a justification. The accountable-justification intervention was based on accountability reportedly improving the accuracy of decision-making and public justification evoking reputational concerns. Clinicians will seek to preserve their reputation by following injunctive norms (i.e., clinical guidelines) more closely. This approach also significantly decreased the mean antibiotics prescribing rates.

Another before-and-after intervention study [67] used a clinical-justification intervention in CDS alerts prompted by a CT order being placed for the same body part that had undergone CT within the previous 90 days. The order could only be placed if a provider overriding the repeat-CT alert selected a clinical justification from predefined options. Adding such a requirement was found to modestly but significantly improve the impact of repeat-CT decision support (a relative change of $23 \%$ ), with the overall effect of preventing 1 in 13 repeat-CT orders.

The findings for peer comparison and accountable justification combined with social norms suggest that outcomes can be improved when using achievable benchmarks by applying nudging interventions that have foundations in social decision-making. A peer-comparison intervention can allow health-care providers with fewer resources to improve the quality of health care.

\subsection{Framing Effect}

The framing effect is one of the better-studied aspects of clinical decision-making biases in both clinicians and patients. The preferences of decision makers for different options are influenced by how equivalent information is formulated or framed. Framing outcomes in terms of gain, such as saving lives or winning money, make people more risk-averse and likely to choose a smaller certain gain over a possible but uncertain larger gain. In contrast, framing outcomes in terms of losses, such as losing lives or money, make people less risk-averse in order to avoid a loss [62]. In other words, individuals are more willing to accept risk 
when they perceive something as a potential loss, and they tend to avoid risk when they perceive a potential gain.

CDS examples appear frequently in research on framing. Armstrong et al. [68] asked their study participants to imagine that they had lung cancer, and gave them probability-of-survival and life-expectancy data for two alternative treatments: surgery and radiation. The data were presented in a positive or "survival" frame to half of the participants, and in a negative or "mortality" frame to the others. The "survival" participants were told that 90 of 100 people receiving surgery will live through the procedure, with 68 being alive after one year and 34 being alive after five years; whereas all of 100 people receiving radiation will live through the treatment, with 77 being alive after one year and 22 being alive after five years. The "mortality" participants received the same objective information presented in terms of the number of people who will die. The participants preferred radiation therapy over surgery $44 \%$ of the time in the mortality frame but only $18 \%$ of the time in the survival frame. These observations imply that preferences vary with how identical objective information is presented.

Tannenbaum et al. [28] examined how grouping menu items systematically affected the prescribing practices of primary-care providers. They used clinical vignettes that described typical signs and symptoms for ARTIs (Acute Respiratory Tract Infections), and asked providers to choose treatments from a menu of options randomly assigned to one of two menu partitions. For antibiotics-inappropriate vignettes, the treatment menu either listed over-the-counter medications individually while grouping prescriptions together, or displayed the reverse partition. Comparing the results across vignettes revealed that there was an $11.5 \%$ reduction in choosing aggressive treatment options (e.g., broad-spectrum antibiotics) when such options were grouped compared to when the same options were listed individually. A randomized clinical trial [35] examined the effects of presenting different benefits and risks in four different formats on the intention of patients to accept low-value or potentially low-value screening services: prostate cancer screening in men aged 50-69 years, osteoporosis screening in low-risk women aged 50-64 years, or colorectal cancer screening in men and women aged 76-84 years. While no differences were found in terms of changes in intentions and other outcomes, the authors found that the format of numbers plus a framed presentation was effective for numerate patients. A very recent study [36] found that the ordering of advanced medical imaging procedures was affected by framed information designed to show physicians guideline rules, malpractice cases, and costs.

The findings of these studies imply that the treatment choices of providers can be influenced by how menu options or relevant messages are displayed, and hence that the layout of EHR order sets and design should not be arbitrary.

\subsection{Status-Quo Bias (Default Bias)}

The concept of opting out is referred to as default bias in behavioral economics. Opt-out means a preferred behavior occurs automatically but can be disregarded, while opt-in means that active steps must be taken to perform a preferred behavior. Opt-out makes the target behavior easier and strongly signals the suggested course of action. Status-quo bias is the similar phenomenon of preferring the current state of affairs. Such behavior can obviously lead to bad decisions, and famous examples of government policies that support status-quo are a government scheme in the United States for opting out of retirement savings [1], the Save More Tomorrow program [69], and an organ donation program [70].

Bourdeaux et al. [71] examined the impact of using default ventilator settings consistent with low tidal-volume targets and a large dashboard with alerts for excessive tidal volumes in the surgical intensive-care unit of a tertiary hospital. They analyzed 2,144 consecutive patients who received controlled mechanical ventilation for more than one hour, and found that variations in the default ventilator settings and using a dashboard can significantly influence clinical decision-making. Schuler et al. [72] applied the same technique to modify the antibiotics order set for discharge prescriptions with the aim of decreasing how long antibiotics were prescribed for uncomplicated skin and soft-tissue infections in a children's hospital, and found a sustained improvement in prescribing practices over a six-month period. Default bias could be considered advantageous since it presents providers with a default option that maximizes benefits and minimizes risks.

\subsection{Heuristics}

A heuristic is any practical approach to problem solving, learning, or discovery that can achieve immediate goals while not being guaranteed to be optimal or perfect $[1,16$, 62]. Where it is impossible or impractical to find an optimal solution, a heuristic can be used to find a satisfactory solution without the cognitive load of making a decision. Examples of this include using a rule of thumb, an educated guess, an intuitive judgment, guesstimate, stereotyping, profiling, or common sense. Heuristics work well under constraints of time pressure and uncertainty precisely because they ignore irrelevant information and streamline decision-making. They mostly generate good outcomes, but they can also draw attention to incorrect contextual cues that lead to predictable errors of judgment (biases). Several types of bias in Table 1 are frequently cited in health care.

One randomized study [39] noted that patients who do not have clearly defined values or preferences when asked to make decisions may construct preferences to justify their choices. Novel persuasive video interventions with recorded vignettes were used to help patients trust and accept controversial, evidence-based screening medical recommendations, and produced significant changes in the screening intentions. Other studies [37, 38] found that exposing emergency room physicians to video games improved triage decision-making in a validated virtual simulation compared to using apps based on traditional didactic education.

\subsection{Overconfidence Bias}

Behavioral economics suggests that errors in probability judgments are common, including overestimations of both past appropriate behavior and future success. Numerous studies 
have indicated that clinicians tend to overestimate their recent utilization of best practices, from vaccinations to evidence-based assessments of high-risk patients [73-75]. Reliable techniques for reducing overconfidence bias have not yet been reported in the behavioral economics literature. Some clinicians might be more receptive to prompts about best practices if they receive feedback that contrasts their self-perceived quality of care they have recently provided to patients with more objective sources of information or peer comparison. The existence of overconfidence bias should reassure developers of CDS interventions that clinicians may sometimes unjustifiably dismiss the need for such reminders.

Forrest et al. [76] assessed the effects of EHR-based CDS and physician performance feedback on adherence to guidelines for acute otitis media and otitis media with effusion. In a factorial-design cluster randomized trial of primary-care practices, those authors developed a CDS system recommending guideline-based practice with monthly feedback to physicians reporting their adherence to guideline-based care. CDS and performance feedback were each found to be effective at improving adherence to guidelines, but with their combination being no better. Gerber et al. [77] applied 1 year of personalized quarterly auditing and feedback about prescribing practice for bacterial and viral ARTIs or usual practice. They found an improved adherence to prescribing guidelines for common bacterial ARTIs, with a decrease in off-guideline prescribing for children with pneumonia, but with no effect on the prescribing of antibiotics for viral infections. Saposnik et al. [43] found that the herding of physicians but not their overconfidence or tolerance to uncertainty affected the management of multiple sclerosis in a prospective study.

\subsection{Other Concepts}

The IKEA effect [60], salience [58, 59], stewardship principle [78], and ordering effect [55] are also reportedly useful methods to apply to CDS. The IKEA effect refers to people overvaluing a product to which they have contributed time and effort. This could be implemented in the clinical environment by involving front-line clinicians in designing CDS systems and allowing them to make small changes to practice guidelines to promote their local ownership and adoption. Salience refers to making important material distinctions so that they will be noticed by clinicians, which could be implemented using atypical messages, unusual font colors, and novel visual images in the usability design of a CDS interface. The stewardship principle was applied to leverage the implementation of an electronic weight-based vancomycin order set in a computerized physician order-entry system to increase the rate of appropriate dosing [79].

\section{Discussion}

The informatics field includes many concepts related to behavioral economics and human biases. These techniques offer novel viewpoints about human biases and the opportunity to use them to change clinician behaviors. For example, current medication alerts are a simple and very common type of CDS exhibiting override rates ranging from $24 \%$ to $98 \%$ worldwide depending on the alert type and study site [80]. Interventions for reducing high override rates have exhibited variable success [81], with proposed mechanisms including alert fatigue, habituation, and human resistance to CDS. Our research team has found that override variations are related to the specificity of CDS rules and task characteristics, and physician-level differences [82]. Our observations on clinician behaviors suggest that there are two types of high over-riders (experienced and inexperienced) who exhibit different characteristics and override patterns, and hence may require different approaches. Providing frequent information such as peer comparison with performance feedback or displaying information effectively using framing bias could be helpful. Behavioral approaches represent a simple and practical option. Issues of informed consent, physician-patient communication, patient adherence, and physician accuracy in diagnoses and treatments are considered to be influenced by biases and heuristics, and new social and cognitive approaches are needed to address them $[9,83]$.
Changing decision-making or behavior of clinicians has been challenging in many care domains. Various interventions such as clinician education, audits and feedback, and financial or regulatory incentives have been used, but these have only been moderately successful and have variable sustainability, especially for education. New interventions that utilize insights from behavioral economics and social psychology present novel opportunities to produce larger and more-enduring effects with CDS. These interventions could take into account a growing body of research indicating that individuals act within broad social contexts and behave in ways that are not always rational but may still be predictable [20,84].

\subsection{Future Directions}

Analytic aids for improving clinical decision-making and promoting evidence-based medicine should ultimately be combined with CDS functions. Such an approach should improve decision-making by encouraging clinicians to focus on the most-relevant information and assign appropriate weightings to that information, even when the weightings come from the clinicians themselves. The demonstrated susceptibility of clinicians to various biases when they are making decisions indicates the desirability of further efforts to reduce possible biases and improve the quality of clinical decision-making. This could include improving the design of evidence-based services and CDS tools and making them more accessible and user-friendly in clinical settings.

\subsection{Study Limitations}

This study reviewed the current literature on the use of behavioral economics concepts in the design and implementation of CDS systems, but relevant studies could have been missed by our manual searching method.

\section{Conclusions}

CDS systems are designed to improve care, but one of their key limitations has been that providers often ignore suggestions that 
would improve clinical care. It is therefore important to make suggestions that are more likely to result in the best choices. CDS systems have the potential to change the way medicine is taught, since responding to them well will become a key skill [85]. Clinicians are affected by their experiences, intuition, and cognitive shortcuts when making clinical decisions, and can be vulnerable to multiple cognitive biases. One method of addressing this problem is to apply behavioral economics approaches and the heuristics of cognitive psychology in CDS interventions. Several recent studies have shown that such approaches are more likely to change clinician behaviors in positive ways compared to using more traditional approaches.

\section{Acknowledgements}

This study was supported by a Korea Research Foundation Grant funded by the Korean Government (MOEHRD Grant No. NRF-2016R1D1A1A09919502). D.W.B. was sponsored by the Centers for Education and Research on Therapeutics, Agency for Healthcare Research and Quality, Rockville, MD, USA (CERT Grant No. U19HS021094).

\section{References}

1. Thaler RH, Sunstein CR. Nudge: Improving decisions about health, wealth, and happiness. New Haven, CT: Yale University Press; 2008.

2. Johnson EJ, Shu SB, Dellaert BG, Fox C, Goldstein DG, Häubl G, et al. Beyond nudges: Tools of a choice architecture. Marketing Letters 2012;23(2):487-504.

3. Cialdini RB, Goldstein NJ. Social influence: Compliance and conformity. Annu Rev Psychol 2004:55:591-621.

4. Schultz PW, Nolan JM, Cialdini RB, Goldstein NJ, Griskevicius V. The constructive, destructive, and reconstructive power of social norms. Psychol Sci 2007;18(5):429-34.

5. Burchell K, Rettie R, Patel K. Marketing social norms: social marketing and the 'social norm approach'. Journal of Consumer Behaviour 2013;12(1):1-9.

6. Ubel PA. What should I do, doc?: Some psychologic benefits of physician recommendations. Arch Intern Med 2002;162(9):977-80.

7. Blumenthal-Barby JS, Burroughs H. Seeking better health care outcomes: the ethics of using the "nudge". Am J Bioeth 2012;12(2):1-10.

8. Purnell JQ, Thompson T, Kreuter MW, McBride TD. Behavioral Economics: "Nudging" Underserved Populations to Be Screened for Cancer. Prev Chronic Dis 2015;12:E06.
9. Croskerry P. The importance of cognitive errors in diagnosis and strategies to minimize them. Acad Med 2003;78(8):775-80.

10. Elstein AS, SchwarzA. Clinical problem solving and diagnostic decision making: selective review of the cognitive literature. BMJ 2002;324(7339):729-32.

11. Jaspers MW, Smeulers M, Vermeulen H, Peute LW. Effects of clinical decision-support systems on practitioner performance and patient outcomes: a synthesis of high-quality systematic review findings. J Am Med Inform Assoc 2011;18(3):327-34.

12. Pearson S-A, Moxey A, Robertson J, Hains I, Williamson M, Reeve J, et al. Do computerised clinical decision support systems for prescribing change practice? A systematic review of the literature (1990-2007). BMC Health Serv Res 2009;9(1):154.

13. Shortliffe EH, Cimino JJ. Biomedical informatics: computer applications in health care and biomedicine: Springer Science \& Business Media; 2013.

14. Greenes RA. Clinical decision support: the road ahead: Academic Press; 2011.

15. Gong CL, Hay JW, Meeker D, Doctor JN. Prescriber preferences for behavioural economics interventions to improve treatment of acute respiratory infections: a discrete choice experiment. BMJ Open 2016;6(9):e012739.

16. Blumenthal-Barby JS, Krieger H. Cognitive biases and heuristics in medical decision making: a critical review using a systematic search strategy. Med Decis Making 2015;35(4):539-57.

17. Hallsworth M, Chadborn T, Sallis A, Sanders M, Berry D, Greaves F, et al. Provision of social norm feedback to high prescribers of antibiotics in general practice: a pragmatic national randomised controlled trial. Lancet 2016;387(10029):1743-52.

18. Ranji S, Steinman M, Shojania K, Sundaram V, Lewis R, Arnold S, et al. Antibiotic prescribing behavior. Closing the quality gap: a critical analysis of quality improvement strategies. Technical Review 2006;9:255-61.

19. Kahneman D. Thinking, fast and slow: Macmillan; 2011.

20. Ariely D. Predictably irrational: HarperCollins New York; 2008.

21. Rooze S, editor. Nudge: Improving Decisions about Health, Wealth and Happiness. Amsterdam Law Forum; 2009.

22. Hough DE. Irrationality in health care: what behavioral economics reveals about what we do and why. Stanford University Press; 2013.

23. Platt ML, Huettel SA. Risky business: the neuroeconomics of decision making under uncertainty. Nat Neurosci 2008;11(4):398.

24. Lee D. Neuroeconomics: Best to go with what you know? Nature 2006;441(7095):822-3.

25. Rice T. The behavioral economics of health and health care. Annu Rev Public Health 2013;34:431-47.

26. Loewenstein G, Brennan T, Volpp KG. Asymmetric paternalism to improve health behaviors. JAMA 2007;298(20):2415-7.

27. Cohen J. A coefficient of agreement for nominal scales. Educ Psychol Meas 1960;20(1):37-46.

28. Tannenbaum D, Doctor JN, Persell SD, Friedberg MW, Meeker D, Friesema EM, et al. Nudging physician prescription decisions by partitioning the order set: results of a vignette-based study. J
Gen Intern Med 2015;30(3):298-304.

29. Meeker D, Linder JA, Fox CR, Friedberg MW, Persell SD, Goldstein NJ, et al. Effect of behavioral interventions on inappropriate antibiotic prescribing among primary care practices: a randomized clinical trial. JAMA 2016;315(6):562-70.

30. Persell SD, Friedberg MW, Meeker D, Linder JA, Fox CR, Goldstein NJ, et al. Use of behavioral economics and social psychology to improve treatment of acute respiratory infections (BEARI): rationale and design of a cluster randomized controlled trial [1RC4AG039115-01]-study protocol and baseline practice and provider characteristics. BMC Infect Dis 2013;13(1):290.

31. McHugh ML. Interrater reliability: the kappa statistic. Biochem Med (Zagreb) 2012;22(3):276-82.

32. Jensen-Doss A, Haimes EMB, Smith AM, Lyon $\mathrm{AR}$, Lewis CC, Stanick CF, et al. Monitoring treatment progress and providing feedback is viewed favorably but rarely used in practice. Adm Policy Ment Hlth 2018;45(1):48-61.

33. Chauhan BF, Jeyaraman M, Mann AS, Lys J, Skidmore B, Sibley KM, et al. Behavior change interventions and policies influencing primary healthcare professionals' practice-an overview of reviews. Implement Sci 2017 Jan 5;12(1):3.

34. Rudolf JW, Dighe AS, Coley CM, Kamis IK, Wertheim BM, Wright DE, et al. Analysis of Daily Laboratory Orders at a Large Urban Academic Center A Multifaceted Approach to Changing Test Ordering Patterns. Am J Clin Pathol 2017 Aug;148(2):128-35.

35. Sheridan SL, Sutkowi-Hemstreet A, Barclay C, Brewer NT, Dolor RJ, Gizlice Z, et al. A Comparative Effectiveness Trial of Alternate Formats for Presenting Benefits and Harms Information for Low-Value Screening Services A Randomized Clinical Trial. JAMA Intern Med 2016 Jan;176(1):31-40.

36. Gimbel RW, Pirrallo RG, Lowe SC, Wright DW, Zhang L, Woo M-J, et al. Effect of clinical decision rules, patient cost and malpractice information on clinician brain CT image ordering: a randomized controlled trial. BMC Med Inform Decis Mak 2018;18(1):20.

37. Mohan D, Farris C, Fischhoff B, Rosengart MR, Angus DC, Yealy DM, et al. Efficacy of educational video game versus traditional educational apps at improving physician decision making in trauma triage: randomized controlled trial. BMJ 2017 Dec 13;359.

38. Mohan D, Rosengart MR, Fischhoff B, Angus DC, Farris C, Yealy DM, et al. Testing a videogame intervention to recalibrate physician heuristics in trauma triage: study protocol for a randomized controlled trial. BMC Emerg Med 2016 Nov 11;16(1):44.

39. Saver BG, Mazor KM, Luckmann R, Cutrona SL, Hayes M, Gorodetsky T, et al. Persuasive Interventions for Controversial Cancer Screening Recommendations: Testing a Novel Approach to Help Patients Make Evidence-Based Decisions. Ann Fam Med 2017 Jan;15(1):48-55.

40. Schwartz PH, Perkins SM, Schmidt KK, Muriello PF, Althouse S, Rawl SM. Providing Quantitative Information and a Nudge to Undergo Stool Testing in a Colorectal Cancer Screening Decision Aid: A Randomized Clinical Trial. Med Decis Making 
2017 Aug;37(6):688-702.

41. Schnaus MJ, Michalik M, Skarda P. Effects of Electronic Medical Record Display on Provider Ordering Behavior: Leveraging the EMR to Improve Quality and Costs. Am J Med 2017 Dec;130(12):1366-71.

42. Saposnik G, Maurino J, Sempere AP, Ruff CC, Tobler PN. Herding: a new phenomenon affecting medical decision-making in multiple sclerosis care? Lessons learned from DIScUTIR MS. Patient Prefer Adher 2017:11:175-80.

43. Saposnik G, Sempere AP, Raptis R, Prefasi D, Selchen D, Maurino J. Decision making under uncertainty, therapeutic inertia, and physicians' risk preferences in the management of multiple sclerosis (DIScUTIR MS). BMC Neurol 2016 May 4;16.

44. Sedikides C, Herbst KC, Hardin DP, Dardis GJ. Accountability as a deterrent to self-enhancement: The search for mechanisms. J Pers Soc Psychol 2002;83(3):592-605.

45. Lerner JS, Tetlock PE. Accounting for the effects of accountability. Psychol Bull 1999;125(2):255-75.

46. Goldstein NJ, Cialdini RB, Griskevicius V. A room with a viewpoint: Using social norms to motivate environmental conservation in hotels. J Consum Res 2008;35(3):472-82.

47. Tversky A, Kahneman D. The framing of decisions and the psychology of choice. Science 1981;211(4481):453-8.

48. Samuelson W, Zeckhauser R. Status quo bias in decision making. J Risk Uncertainty 1988;1(1):7-59.

49. Glimcher PW, Camerer CF, Fehr E, Poldrack RA. Neuroeconomics: Decision Making and the Brain. Elsevier; 2009.

50. Levy I, Snell J, Nelson AJ, Rustichini A, Glimcher PW. Neural representation of subjective value under risk and ambiguity. J Neurophysiol 2009;103(2):1036-47.

51. Anderson LR, Mellor JM. Predicting health behaviors with an experimental measure of risk preference. J Health Econ 2008;27(5):1260-74.

52. Sethi-Iyengar S, Huberman G, Jiang W. How much choice is too much? Contributions to 401 (k) retirement plans. In: Mitchell OS, Utkus, SP. Pension design and structure: New lessons from behavioral finance; 2004. p. 84-7.

53. Opel DJ, Omer SB. Measles, mandates, and making vaccination the default option. JAMA Pediatr 2015;169(4):303-4.

54. Dayan E, Bar-Hillel M. Nudge to nobesity II: Menu positions influence food orders. Judgm Decis Mak 2011;6(4):333-42.

55. Kjær T, Bech M, Gyrd Hansen D, Hart Hansen K. Ordering effect and price sensitivity in discrete choice experiments: need we worry? Health Econ 2006;15(11):1217-28.

56. White JS, Dow WH. Intertemporal choices for health. Behavioral Economics and Public Health; 2015. p. 62.

57. Heath C, Heath D. Chapter 8: Tweak the Environment. Switch: How to Change Things When
Change is Hard. New York, N.Y.: Broadway Books; 2010.

58. Taylor SE, Fiske ST. Salience, Attention, and Attribution: Top of the Head Phenomena. Advances in Experimental Social Psychology. Elsevier; 1978. p. 249-88.

59. Stryker S, Serpe RT. Identity salience and psychological centrality: Equivalent, overlapping, or complementary concepts? Soc Psychol Q 1994:16-35.

60. Norton MI, Mochon D, Ariely D. The IKEA effect: When labor leads to love. J Consum Psychol 2012;22(3):453-60

61. Easley D, Kleinberg J. Chapter 16: Information Cascades. Networks, Crowds, and Markets: Reasoning about a Highly Connected World. Cambridge: Cambridge University Press; 2010. p. 483-508.

62. Bornstein BH, Emler AC. Rationality in medical decision making: a review of the literature on doctors' decision making biases. J Eval Clin Pract 2001;7(2):97-107.

63. Davis DA, Mazmanian PE, Fordis M, Van Harrison RR, Thorpe KE, Perrier L. Accuracy of physician self-assessment compared with observed measures of competence: A systematic review. JAMA 2006;296(9):1094-102.

64. Croskerry P. From mindless to mindful practicecognitive bias and clinical decision making. NEngl J Med 2013;368(26):2445-8.

65. Spranca M, Minsk E, Baron J. Omission and commission in judgment and choice. J Exp Soc Psychol 1991;27(1):76-105.

66. Kiefe CI, Allison JJ, Williams OD, Person SD, Weaver MT, Weissman NW. Improving quality improvement using achievable benchmarks for physician feedback: a randomized controlled trial. JAMA 2001;285(22):2871-9.

67. O'Connor SD, Sodickson AD, Ip IK, Raja AS, Healey MJ, Schneider LI, et al. Journal club: Requiring clinical justification to override repeat imaging decision support: impact on CT use. AJR Am J Roentgenol 2014;203(5):W482-90.

68. Armstrong K, Schwartz JS, Fitzgerald G, Putt M, Ubel PA. Effect of framing as gain versus loss on understanding and hypothetical treatment choices: survival and mortality curves. Med Decis Making 2002;22(1):76-83.

69. Thaler RH, Benartzi S. Save more tomorrow ${ }^{\mathrm{TM}}$ : Using behavioral economics to increase employee saving. J Polit Econ 2004;112(S1):S164-S87.

70. Johnson EJ, Goldstein D. Do defaults save lives? Science 2003;302(5649):1338-9.

71. Bourdeaux CP, Thomas MJ, Gould TH, Malhotra G, Jarvstad A, Jones T, et al. Increasing compliance with low tidal volume ventilation in the ICU with two nudge-based interventions: evaluation through intervention time-series analyses. BMJ Open 2016;6(5):e010129.

72. Schuler CL, Courter JD, Conneely SE, Frost MA, Sherenian MG, Shah SS, et al. Decreasing duration of antibiotic prescribing for uncomplicated skin and soft tissue infections. Pediatrics 2016;137(2):e20151223.

73. Gordon MK, Baum RA, Gardner W, Kelleher KJ, Langberg JM, Brinkman WB, et al. Comparison of performance on $\mathrm{ADHD}$ quality of care indicators: practitioner self-report versus chart review. JAtten Disord 2016:1087054715624227.

74. Rickert D, Santoli J, Shefer A, Myrick A, Yusuf $H$. Influenza vaccination of high-risk children: what the providers say. Am J Prev Med 2006;30(2):111-8.

75. Alexander GC, Humensky J, Guerrero C, Park H, Loewenstein G. Brief report: Physician narcissism, ego threats, and confidence in the face of uncertainty. J Appl Soc Psychol 2010;40(4):947-55.

76. Forrest CB, Fiks AG, Bailey LC, Localio R, Grundmeier RW, Richards T, et al. Improving adherence to otitis media guidelines with clinical decision support and physician feedback. Pediatrics 2013;131(4):e1071-81.

77. Gerber JS, Prasad PA, Fiks AG, Localio AR, Grundmeier RW, Bell LM, et al. Effect of an outpatient antimicrobial stewardship intervention on broad-spectrum antibiotic prescribing by primary care pediatricians: a randomized trial. JAMA 2013;309(22):2345-52.

78. Hernandez M. Toward an understanding of the psychology of stewardship. Acad Manage Rev 2012;37(2):172-93.

79. Hall AB, Montero J, Cobian J, Regan T. The effects of an electronic order set on vancomycin dosing in the ED. Am J Emerg Med 2015;33(1):92-4.

80. Nanji KC, Slight SP, Seger DL, Cho I, Fiskio JM, Redden LM, et al. Overrides of medication-related clinical decision support alerts in outpatients. J Am Med Inform Assoc 2014;21(3):487-91.

81. Schreiber R, Gregoire JA, Shaha JE, Shaha SH. Think time: A novel approach to analysis of clinicians' behavior after reduction of drug-drug interaction alerts. Int J Med Inform 2017;97:59-67.

82. Cho I, Lee Y, Lee J-H, Bates DW. Wide Variation and Patterns of Physicians' Responses to DrugDrug Interaction Alerts. Int J Qual Health Care 2018 May8.

83. Ubel P. Critical Decisions: How You and Your Doctor Can Make the Right Medical Choices Together. 1st ed. New York: HarperOne; 2012.

84. DellaVigna S. Psychology and economics: Evidence from the field. J Econ Lit 2009;47(2):315-72.

85. Berner ES. Clinical decision support systems: Springer; 2007

Correspondence to:

Insook Cho, RN, PhD.

Nursing Department, Inha University

Inharo 100, Namgu, Incheon 22212

South Korea

Tel: + 82328608201

Fax: +82328748201

E-mail: insook.cho@inha.ac.kr 